\title{
Assessment of the infectivity of corneal buttons taken from hepatitis B surface antigen seropositive donors
}

\author{
Ahmad Khalil, Mohamed Ayoub, Kouka Saad El-Din Abdel-Wahab, Azza El-Salakawy
}

Research Institute of Ophthalmology, Cairo, Egypt

A Khalil

Department of Ophthalmology, Faculty of Medicine, Cairo University, Cairo, Egypt

$M$ Ayoub

Department of Microbiology, Faculty of Medicine for Girls, Al-Azhar University,

Cairo, Egypt

K S El-Din Abdel-Wahab

Department of Microbiology, Faculty of Medicine for Girls, Al-Azhar University, Cairo, Egypt

A El-Salakawy

Correspondence to: Ahmad Khalil, MD, Department of

Ophthalmology, Faculty of

Medicine, Kyushu

University, 3-1-1 Maidashi,

Higashi ku, Fukuoka, 812 ,

Japan.

Accepted for publication 3 October 1994

\begin{abstract}
Sixty one corneas taken from 33 hepatitis B surface antigen (HBsAg) seropositive donors and 20 control corneas taken from 12 HBsAg seronegative donors were tested for the presence of $\mathrm{HBs} A \mathrm{~g}$ using reversed passive haemagglutination (RPHA) and enzyme linked immunosorbent assay (ELISA) and for the presence of hepatitis $B$ virus core DNA (HBVcDNA) using the hybridisation technique in their epithelium, stroma endothelium, and storage media. HBsAg was detected by ELISA in the epithelium of one cornea $(1 \cdot 6 \%)$, in the stroma endothelial suspensions of six corneas $(9.8 \%)$, and in the storage media of five corneas $(8 \cdot 2 \%)$. HBVcDNA was detected for the first time in the cornea; in the epithelium of four corneas $(6 \cdot 6 \%)$, stroma endothelium of nine corneas $(14 \cdot 8 \%)$, and the storage media of five corneas $(8 \cdot 2 \%)$. The control corneas were negative for HBsAg, while HBVcDNA was detected in the stroma endothelium of two corneas $(10 \%)$ and in the media of two corneas $(10 \%)$. This study confirmed that HBV can be present in the human cornea. Preservation in corneal storage media for up to 6 days could not eliminate the virus from the cornea. The possibility of $\mathrm{HBV}$ transmission through corneal transplantation should not be overlooked. (Br f Ophthalmol 1995; 79: 6-9)
\end{abstract}

Transmission of donor disease to the recipient through corneal transplantation, though rare, is a recognised event. ${ }^{1}$ Three cases of viral $\mathrm{B}$ hepatitis possibly transmitted via keratoplasty have been reported. ${ }^{12}$ Nevertheless, the high contagiousness of hepatitis $B$ virus and the seriousness of the disease it produces point to the importance of elimination of any potential source of transmission. ${ }^{3}$

Hepatitis $B$ virus (HBV) belongs to the family Hepadnaviridae, which displays prominent hepatotropism. However, several reports have demonstrated that the hepatitis viruses gain access to cells other than hepatocytes. ${ }^{4-6}$ Hepatitis B surface antigen (HBsAg) seropositive donors are excluded from eye banks as they are considered a potential source of transmission of viral B hepatitis. However, this antigen has been found so far in corneal epithelium but not in other corneal tissues. ${ }^{7}$ While HBsAg is located on the infectious virus envelope, it is also found on non-infectious particles. ${ }^{8}$ Therefore, the detection of HBsAg in a tissue does not imply its infectivity. Owing to a better understanding of this virus and to the use of viral DNA as a marker of complete replicative forms, it is now possible to confirm the state of HBV infectivity in tissues. ${ }^{9}$ Both enzyme linked immunosorbent assay (ELISA) and detection of HBV DNA by hybridisation have been used previously for the detection of HBV markers in different tissue extracts. ${ }^{2} 510$

The aim of this study was to correlate HBsAg seropositivity in corneal donors with the presence or absence of both HBsAg and hepatitis B virus core DNA (HBVcDNA) in corneal tissues.

\section{Materials and methods}

Sixty one corneoscleral buttons from 33 HBsAg seropositive donors were obtained from Cairo University Eye Bank (CUEB). Twenty corneoscleral buttons from $12 \mathrm{HBsAg}$ seronegative donors were used as controls. These control corneas were not used for surgery because of causes other than $\mathrm{HBsAg}$ seropositivity. Seropositivity of these donors was tested by latex agglutination technique using the commercial kit supplied by Stanbio (Texas, USA); Stanbio hepatitis B procedure No 1195.

Before the results of serum testing five corneoscleral rims were preserved in $20 \mathrm{ml}$ of Dexsol medium and 76 in $20 \mathrm{ml}$ of McCareyKaufman (MK) medium. Both media were supplied by Chiron Ophthalmics (California, USA). All specimens were kept in the CUEB refrigerator at $4^{\circ} \mathrm{C}$ until seropositivity was confirmed.

All specimens were manipulated with sterile gloves in the chamber of a laminar airflow apparatus. The bottle was opened, the corneoscleral button was held using a fixation forceps, removed from the bottle, washed with saline solution, and placed (epithelial side up) in a sterile petri dish. Using the fixation forceps and scissors, the scleral rim was excised and thrown away. With the cornea firmly held down on the petri dish, the epithelium was scraped with No 11 surgical blade, then washed from the 
Table 1 Results of $H B s A g$ and $H B V c D N A$ testing in epithelium, stroma endothelium, and preservative media of 61 corneas taken from 33 donors with $\mathrm{HBs} \mathrm{Ag}$ antigenaemia

\begin{tabular}{lccc}
\hline & Epithelium & $\begin{array}{l}\text { Stroma } \\
\text { endothelium }\end{array}$ & Medium \\
\hline HBsAg & $1(1 \cdot 6 \%)$ & $6(9 \cdot 8 \%)$ & $5(8 \cdot 2 \%)$ \\
HBVcDNA & $4(6 \cdot 6 \%)$ & $9(14 \cdot 8 \%)$ & $5(8 \cdot 2 \%)$ \\
$\begin{array}{l}\text { Positives for both } \\
\text { markers together }\end{array}$ & $5(8 \cdot 2 \%)$ & $12(19 \cdot 7 \%)$ & $10(16 \cdot 4 \%)$ \\
\hline
\end{tabular}

$\mathrm{HBsAg}=$ hepatitis $B$ surface antigen.

HBVCDNA=hepatitis $B$ virus core DNA.

blade down into a tube with $0.25 \mathrm{ml}$ of saline solution.

The stroma endothelium was again washed with saline solution and fragmented with scissors into the smallest pieces possible (approximately $1 \mathrm{~mm}$ in diameter), then put into a tube and $1 \mathrm{ml}$ of saline solution added. The tube containing the stroma endothelial pieces was then put in a sonicator at $460 \mathrm{~W} / \mathrm{cm}^{2}$ for 10 minutes. All three specimens - that is, epithelial suspension, stroma endothelial suspension, and corneal preservation medium, were then kept in the refrigerator at $4^{\circ} \mathrm{C}$. All samples were first tested for HBsAg using Albugam's (Zurich, Switzerland) reversed passive haemagglutination (RPHA) test kit. HBsAg was also tested for in the samples with ELISA using the commercial kit supplied by Hoechst (Marburg, Germany); Enzygnost HBsAg monoclonal. All samples were tested for the presence of $\mathrm{HBVCDNA}$ in the virology laboratories of Al-Azhar University with the kit supplied by Dupont (California, USA); Hepatitis B virus (core antigen) SNAP hybridisation system (Catalogue No NEP-004) according to the manufacturer's manual. No attempt was made to extract DNA. The assays were performed on the crude sonicate. The membranes were prepared and assembled on the manifold apparatus. Samples, positive control (supplied), and negative control were added and prepared for hybridisation which was carried out for 15 minutes at $55^{\circ} \mathrm{C}$. Membranes were then washed as described in the manual. Colour was detected using an alkaline phosphatase buffer substrate system at room temperature.

\section{Results}

Of the 61 corneas obtained from HBsAg seropositive donors, none of the specimens was found positive for HBsAg using the RPHA technique. Using ELISA, HBsAg was detected in 10 corneas, their media, or both $(16.4 \%)$ taken from eight donors. A positive signal for HBVcDNA was detected in 15 corneas, their media, or both $(24.6 \%)$ taken from nine donors.

Table 2 Results of $H B s A g$ and $H B V c D N A$ testing in epithelium, stroma endothelium, and preservative media of 20 corneas taken from $\mathrm{HBs} \mathrm{Ag}$ seronegative donors

\begin{tabular}{llll}
\hline & Epithelium & $\begin{array}{l}\text { Stroma } \\
\text { endothelium }\end{array}$ & Medium \\
\hline HBsAg & 0 & 0 & 0 \\
HBVcDNA & 0 & $2(10 \%)$ & $2(10 \%)$ \\
\hline
\end{tabular}

The epithelial scrapings of one cornea $(1.6 \%)$ tested positive for HBsAg using ELISA, while those of another four corneas $(6.6 \%)$ taken from four donors tested positive for $\mathrm{HBVCDNA}$ (Table 1).

The stroma endothelial suspensions of six corneas $(9 \cdot 8 \%)$ taken from four donors were found positive for HBsAg using ELISA, while those of nine corneas $(14.8 \%)$ taken from five donors were positive for HBVcDNA (Table 1). Of the above, three stroma endothelial suspensions from two donors were positive for both HBsAg and HBVcDNA. These positive corneas remained in their preservative media for 1-6 days.

The preservative media of five corneas $(8.2 \%)$ taken from four donors were positive for HBsAg using ELISA. Of these, four were MK and one was Dexsol. One MK medium contained the cornea for just 1 day before preparation, while the other four corneas remained in their media for 3-7 days. The media of another five corneas $(8 \cdot 2 \%)$ taken from three donors tested positive for HBVcDNA (Table 1). All of these media were MK. The period of preservation ranged from 2-8 days. Of the 10 corneas preserved in the media which tested positive for HBsAg or $\mathrm{HBVCDNA}$, one epithelial suspension tested positive for $\mathrm{HBVCDNA}$, two stroma endothelial suspensions were positive only for HBsAg, two were positive only for HBVcDNA, and one was positive for both markers. The total number of corneas giving positive results in their tissues was six. The marker found in corneal tissue was the same found in the medium except in one case in which the corneal tissue was positive only for HBVcDNA while the medium was positive only for HBsAg.

Of the 51 corneas preserved in media which were negative for both markers, the epithelial suspension of one cornea was positive for HBsAg and those of another three corneas were positive for HBVcDNA, one stroma endothelial suspension tested positive only for $\mathrm{HBsAg}$, three tested positive only for $\mathrm{HBVCDNA}$, and two tested positive for both markers. A total of 10 corneas gave positive results.

Of the 20 control corneas obtained from HBsAg seronegative donors, no tissue suspension or medium was positive for HBsAg. The stroma endothelium of two corneas taken from the same donor and the preservative media of another two corneas of two different donors were positive for $\mathrm{HBVcDNA}$ (Table 2). Both of these media were MK.

\section{Discussion}

Since the discovery of the possibility of transmission of some viral diseases through corneal transplantation, it has been questioned whether or not transmission of $\mathrm{HBV}$ infection could possibly occur in the same way. HBsAg was previously detected in tears, ${ }^{3} 11-13$ aqueous, ${ }^{7} 1213$ subretinal fluid, ${ }^{14}$ conjunctiva, corneal epithelium, and uveal tissue. ${ }^{7}$ While this antigen is located on the infectious virus envelope, it is also found on non-infectious 
particles. ${ }^{8}$ Owing to a better understanding of the nature of this virus and to the use of viral DNA as a marker of complete replicative forms, it is now possible to confirm the state of HBV infectivity in tissues. ${ }^{915}$ The hybridisation technique used for HBV DNA detection is highly sensitive. ${ }^{1617}$ It has been used successfully to detect HBV DNA sequences in different minced tissues. ${ }^{6} 10$

In this study, HBsAg could be detected in none of the corneal samples using RPHA. Using ELISA, HBsAg was detected in 10 out of 61 corneas $(16.4 \%)$ taken from seropositive donors. Fifteen corneas $(24.6 \%)$ were positive for $\mathrm{HBVCDNA}$. Failure of detection of $\mathrm{HBsAg}$ in the samples using RPHA points to the low sensitivity of this test. This is in accordance with previously published data. ${ }^{16}$

The presence of HBsAg and HBVcDNA in epithelial samples may be caused by the actual presence of the virus in epithelial cells. Diffusion from perilimbic capillaries is still a possibility. Gastaud et $a l^{3}$ detected both HBsAg and HBV DNA in tears; however, contamination from tears is unlikely as the epithelial surface was washed before scraping.

HBsAg has been detected previously using ELISA in emulsified whole corneas of a seropositive donor. ${ }^{2}$ The positive result could be caused by the presence of HBsAg in the epithelium, stroma, endothelium, or contamination of the endothelial surface from adjacent aqueous. In the current study, however, emulsification was carried out after epithelial scraping followed by washing of both epithelial and endothelial surfaces. Hence, the possibility of viral adherence to the endothelium from adjacent aqueous is minimal. As no attempt was made to separate endothelium from stroma, these positive results may reflect the presence of the virus in endothelium, stroma, or both. As no vascularised corneas were used in the study, the possibility of blood contaminating the samples is unlikely. The occurrence of more positive results for both markers in the stroma endothelial samples than epithelial samples may be attributed to different dilution standards used for both samples. In the mean time, the occurrence of more overall positive results with $\mathrm{HBVcDNA}$ than with HBsAg may reflect the higher sensitivity of molecular hybridisation over other serological tests including ELISA used to detect HBsAg. In one report HBV DNA was detected in $65.2 \%$ of samples negative to HBsAg by RPHA. ${ }^{16}$

Detection of viral markers in the preservative media is probably due to diffusion from the corneal tissue. However, presence of blood traces in the media might be another cause, although blood was not evident grossly in any of the samples.

Of the 10 corneas preserved in media which tested positive for either marker, six corneas were positive for $\mathrm{HBsAg}, \mathrm{HBVcDNA}$, or both in their tissues, while four were negative for both markers. Of the 51 corneas preserved in media which tested negative for both markers, 10 corneas were positive for $\mathrm{HBsAg}$, $\mathrm{HBVcDNA}$, or both in their tissues. So, it is likely that four out of 10 corneas became negative after diffusion of their markers to their storage media. Of these four corneas, one remained in its medium for only 1 day. On the other hand, viral markers in 10 positive corneas failed to diffuse to the surrounding medium in detectable levels, although some of them were kept in their media for up to 6 days. Thus, the storage medium did not have a hypothesised beneficial effect in diluting the virus particles, even with prolonged preservation (up to 6 days). The duration of storage was irrelevant to diffusion of markers to the medium.

The presence of positive results for HBVcDNA in three out of $12 \mathrm{HBsAg}$ seronegative donors may be explained by real absence of HBsAg from the circulation in one stage of the disease (window phase). Alternatively, it can reflect a false negative result associated with latex agglutination. It is also probable that the serum of these seronegative donors did contain amounts of HBsAg too small to be detected by that test. Consequently, HBsAg could not reach detectable levels in their corneas. However, HBVcDNA could be detected with the more sensitive hybridisation technique in the corneas. Probably, these donors and one or more HBsAg seronegatives would be seropositive for HBVcDNA.

Transmission of HBV infection via the conjunctival route can occur as shown by the experimental inoculation of infectious material into the conjunctival sac of a chimpanze ${ }^{18}$ and the possible transmission of the disease to a nurse who had a splash of infective blood onto her eyes. ${ }^{19}$ This study detected that not only the surface antigen but also the viral DNA itself could be present in corneal tissues prepared for surgery, even after storing them for up to 6 days in corneal storage medium. To our knowledge, this is the first published work to search for and document the presence of HBV DNA in the cornea. The conditions of tissues used in this study were nearest to surgical conditions; no vascularised corneas were used, scleral rims were excised, no attempt was made to separate endothelium from stroma, corneoscleral buttons were taken from apparently healthy donors, jaundice was present in only one donor, who oddly did not show any positive results.

While three of 12 donors seronegative for HBsAg were positive for core DNA in corneal tissue/media, there were no cases reported to CUEB of possible transmission of clinical hepatitis after corneal grafting. An unanswered question is whether the amount of the virus present in the tissue constitutes an infectious inoculum when introduced through the eye. What is infectious by a certain route might not be so by another route. Infectious saliva could transmit hepatitis when administered subcutaneously to gibbons, but the same material failed to infect the animals when administered orally. ${ }^{20}{ }^{21}$ Is the amount of the virus present in the cornea so small that it can not introduce infection through the eye which probably needs such a high concentration for the 
infection to be transmitted? Noteworthy too is the fact that despite the presence of HIV in the cornea, ${ }^{22}$ its transmission through corneal transplantation could not be documented with many inadvertent transplantations from seropositive to seronegative recipients. ${ }^{23} 24$

However, until these questions are answered, eye banks should continue the current policy of rejecting tissues of any donor who proves to be HBsAg seropositive. Great care should be taken during handling of tissues even those of HBsAg seronegative donors. Good medical records with accurate history and laboratory investigations should be available for and properly used by the eye bank personnel. This might exclude a seronegative donor with a known history of hepatitis harbouring the virus in his cornea. Routine screening of corneal donors should preferably be done with a more sensitive test. CUEB has replaced latex agglutination by ELISA for screening of corneal donors. Eye surgeons should always bear in mind that they are dealing with tissues and tissue fluids that are potentially contagious. All precautions to protect surgeons and their patients should be sought. After trephining corneas from corneoscleral buttons, corneas may not be covered with the preservative solution but a viscoelastic substance is a good alternative. Residual scleral tissue should be properly disposed of.

1 O'Day DM. Diseases potentially transmitted through corneal transplantation. Ophthalmology 1989; 96: 1133-8. 2 Raber IM, Friedman HM. Hepatitis B surface antigen in corneal donors. Am f Ophthalmol 1987; 104: 255-8.

3 Gastaud P, Baudouin CH, Ouzan D. Detection of HBs antigen, DNA polymerase activity and hepatitis $B$ virus DNA in tears: relevance to hepatitis $B$ transmission by tears. Br F Ophthalmol 1989; 73: 333-6.

4 Romet-Lemonne JL, McLane MF, El-Fassi E, Haseltine WA, Azocar J, Essex M. Hepatitis B virus infection WA, Azocar J, Essex M. Hepatitis B virus infection
cultured human lymphoblastoid cells. Science 1983; 221: cultured

5 Dejean A, Lugassy C, Zafrani S, Tiollais P, Brechot C. Detection of hepatitis $B$ virus DNA in pancreas, kidney and skin of two human carriers of the virus. $\mathcal{f}$ Gen Virol 1984; 65: 651-5.

6 Yoffe B, Burns DK, Bhatt HS, Combes B. Extrahepatic hepatitis B virus DNA sequences in patients with acute hepatitis B infection. Hepatology 1990; 12: 187-92.
7 Boehnke M, von Domarus D. Hepatitis B surface antigen in a donor's eye. Graefes Arch Clin Exp Ophthalmol 1983, 220: $84-6$.

8 Hollinger FB. Hepatitis B virus. In: Fields BN, Knipe DM, Chanock R, Melnick JL, Bandshape RE, eds. Virology. 2nd ed. New York: Raven Press, 1990: 2171-236.

9 Karayiannis P, Novick DM, Lok ASF, Fowler MJF, Monjardino J, Thomas HC. Hepatitis B virus DNA in saliva, urine and seminal fluid of carriers of hepatitis B e antigen. BMf 1985; 290: 1853-5.

10 Molina J, Bartolome J, Moraleda G, Ruiz Moreno M, Rua MJ, Moreno A, et al. Persistence of hepatitis B virus DNA after reduction of viral replication in serum and liver. after reduction of viral rep
$\mathcal{H}$ Med Virol 1992; 38: $11-5$.

11 Darrell RW, Jacob GB. Hepatitis B surface antigen in human tears. Arch Ophthalmol 1978; 96: 674-6.

12 Temel A, Seber E, Guanay M. Detection of hepatitis B surface antigen in aqueous humor. Acta Ophthalmol (Copenh) 1990; 68: 205-8.

13 Koksal I, Cetinkaya K, Aker F. Hepatitis B surface antigen in tears and aqueous humour. A comparative study of serum hepatitis B surface antigen levels. Ophthalmologica 1992; 204: 19-22.

14 Friberg TR, Williamson D. Hepatitis B surface antigen in human subretinal fluid [Letter]. Am f Ophthalmol 1983, 95: 712-3

15 Sunen E, Fernandez de Aranguiz A, De Las Heras B, Gorrino MT, Sarria L, Malave C, et al. Detection of hepatitis $B$ virus DNA in peripheral blood mononuclear cells from patients with various hepatopathies using in situ hybridization [Abstract]. Ann Med Intern 1991; 8: 372-6.

16 Xiao YJ. A study of potential risk of $\mathrm{HBsAg}$ negative with RPHA [English abstract]. Chung-Hua-Ya-Fang-I-HsuehTsa-Chih 1991; 25: 158-60.

17 Diamantis ID, McGandy CE, Pult I, Buhler H, Schmid M, Gudat F, et al. Polymerase chain reaction detects hepatitis $B$ virus DNA in paraffin-embedded liver tissue from patients sero- and histo-negative for active hepatitis B [Abstract]. Virchows Arch A Pathol Anat Histopathol 1992 420: $11-5$.

18 Bond WW, Peterson NJ, Favero MS, Ebert JW, Maynard JE. Transmission of type B viral hepatitis via eye inoculation of a chimpanzee. $\mathcal{F}$ Clin Microbiol 1982; 15: 533-4.

19 Kew MC. Possible transmission of serum (Australia antigen positive) hepatitis via the conjunctiva. Infect Immunol positive) hepatitis

20 Bancroft WH, Snitbhan R, Scott RM, Tingpalapong $M$, Watson WT, Tanticharoenyos $\mathrm{P}$, et al. Transmission of hepatitis $B$ virus to gibbons by exposure to human saliva containing hepatitis B surface antigen. $\mathcal{F}$ Infect Dis 1977 135: $79-85$.

21 Scott RM, Snitbhan R, Bancroft WH, Alter HJ, Tingpalapong $M$. Experimental transmission of hepatitis $B$ virus by semen and saliva. $\mathcal{F}$ Infect Dis 1980; 142: 67-71.

22 Salahuddin SZ, Palestine AG, Heck E, Ablashi D, Luckenbach M, McCulley JP, et al. Isolation of the human T-cell leukemia/lymphotropic virus type III from the cornea. Am $\mathcal{F}$ Ophthalmol 1986; 101: 149-52.

23 Pepose JS, MacRae S, Quinn TC, Ward JW. Serologic markers after the transplantation of corneas from donors infected with human immunodeficiency virus. $A m$ Ophthalmol 1987; 103: 798-801.

24 Schwartz A, Hoffmann F, L'age-Stehr J, Tegzess AM, Offermann $G$. Human immunodeficiency virus transmission by organ donation. Outcome in cornea and kidney recipients. Transplantation 1987; 44: 21-4. 